\title{
Matrimonio, repudio y celibato (Mc 10,1-12; Mt 19,1-12)
}

\section{Marriage, repudiation, celibacy (Mk 10,1-12; Mt 19,1-12)}

\author{
Hugo Orlando Martínez Aldana. Pbro. ${ }^{2}$
}

\section{Resumen}

El objetivo central de este trabajo es el estudio exegético - teológico del pasaje de Mc 10,1-12 y su paralelo en Mt 19,1-12, dando énfasis a las temáticas del matrimonio, el repudio y el celibato. A lo largo del trabajo se entra en diálogo con otros autores, que han estudiado esta misma temática, con el propósito de identificar y proponer nuevas líneas interpretativas de estos pasajes que tienen su importancia propia en el contexto actual. La interpretación del matrimonio que hace Jesús lo reconduce a su fuente y origen, desde la creación, y de esta manera suprime cualquier posibilidad de disolver aquello que Dios mismo ha unido. Por otra parte, se analiza el dicho de Jesús sobre los eunucos con el fin de verificar si estas palabras se constituyen en fundamento bíblico para argumentar el origen del celibato en la Iglesia, o si se hace necesario encontrar una justificación desde otra perspectiva.

Palabras clave: Matrimonio; Repudio; Celibato; Evangelio; Interpretación. Iglesia.

\begin{abstract}
The principal objective of this paper is the exegeticaltheological study of the biblical passage Mc 10,1-12 and its parallel Mt 19,1-12, emphasizing topics of marriage, repudiation and celibate. Throughout this paper it is sought to dialogue with other authors that had studied these same topics with the intent of identifying and proposing new interpretative currents of this passages which have their own importance in the current context. The interpretation of marriage given by Jesus resumes to his source and origin (since creation); and in this way, he eliminates any possibility of disbanding what God has united. On the other hand, Jesus' saying about eunuchs is analyzed with the purpose of verifying if those words are a biblical foundation to argue the origin of celibacy in Church, or whether it is necessary to find a justification from a different approach.
\end{abstract}

Keywords: Marriage; Repudiation; Celibacy; Gospel; Interpretation Church. 


\section{Algunas consideraciones iniciales}

A primera vista, estos textos se presentan como fascinantes a la hora de abordar el estudio, pero también ofrecen aspectos de relativa dificultad (se siguen los textos de la versión griega de Nestle Aland, 28 ed. Se recomienda al lector utilizar la traducción de la Biblia de Jerusalén). De todos modos, nos proponemos ofrecer algunos ítems para la interpretación de estos textos desde la perspectiva de la antropología bíblica. Mc 10,1-12 es una perícopa bien delimitada desde el punto de vista geográfico, de los personajes, del vocabulario y de la temática. Con respecto a la crítica textual nos encontramos ante un texto bastante seguro porque no presenta variantes que merezcan una atención particular. Por otra parte, en el evangelio de Marcos el texto tiene un hilo conductor centrado en la temática de la enseñanza de Jesús. En el capítulo precedente, Jesús, junto con sus discípulos, recorre la región de Galilea, y quiere permanecer de incógnito con el fin de dedicarse total y exclusivamente a la enseñanza de sus discípulos (Mc 9,30). Luego, ellos descienden a Judea, al otro lado del Jordán, donde la multitud se une al grupo para escuchar las enseñanzas de Jesús (Mc 10,1).

Por otra parte, para Mateo, el contexto de la perícopa son los milagros. En efecto, después de haber terminado los discursos dirigidos a la multitud en Cafarnaúm, Jesús desciende a Judea y, seguido por las multitudes, hace milagros (Mt 19,2). La situación geográfica para los dos evangelistas es la misma. Con respecto al relato como tal, Mateo ofrece un orden diferente en el discurso con relación a Marcos y utiliza un vocabulario muy particular. En este sentido, se debe subrayar la particularidad de Mateo en el dicho de Jesús sobre los eunucos el cual hace falta totalmente en Marcos.

En cuanto al esquema de la perícopa en Mateo, la introducción presenta tanto a los interlocutores del diálogo (los fariseos) como a la preguntaproblema: "Puede uno repudiar a su mujer por un motivo cualquiera" (Mt 19,3); luego aparece una doble respuesta (vv. 4-5), que, en un análisis más detallado, puede considerarse como una reelaboración de dos temas distintos: el orden inicial (v.4) y la salida de la casa para formar una pareja, que se vincula, más allá de las convenciones económicas y sociales, para dar vida a un proyecto (formarán una sola carne v.5). A esta respuesta se agrega una máxima aplicada no solo a los contratos matrimoniales sino a una institución prevista por la ley (lo que Dios ha unido), como se puede observar por el uso del verbo "aoristo" indicativo ( $\sigma u v \varepsilon ́ \zeta \varepsilon v \xi \varepsilon v)$ que tiene un carácter atemporal (v.6); sigue una objeción (v.7) que se refiere al uso de una formalidad legal para tomar ventaja; luego una contra-objeción (vv.8-9) a la cual se agrega, como conclusión, una objeción a esta enseñanza como un comentario de los discípulos a la situación que aflora en la comunidad cristiana: "No conviene casarse" (v 10). Esta objeción recibe una nueva respuesta (v. 11) que aclara que cuanto está contenido en ella no está dirigido a todos, sino a quienes ha sido dada la virtud de acoger esta enseñanza ( $\chi \boldsymbol{\chi} \boldsymbol{\omega} \boldsymbol{\rho} \boldsymbol{\varepsilon} \boldsymbol{\omega})$. Finalmente, aparece la sentencia sobre los eunucos (v.12).

Además, encontramos dos pasajes dentro del mismo evangelio de Mateo que hacen referencia al adulterio, ambos se encuentran en el capítulo quinto:

Habéis oído que se dijo: No cometerás adulterio. Pues yo os digo: Todo el que mira a una mujer deseándola, ya cometió adulterio con ella en su corazón (Mt 5,27-28); y también se dijo: El que repudie a su mujer, que le dé acta de divorcio. Pues yo os digo: Todo el que repudia a su mujer, excepto el caso de fornicación, la hace ser adúltera; y el que se case con una repudiada, comete adulterio (Mt 5,31-32). 
Por su parte, el evangelio de Lucas presenta también una enseñanza de Jesús sobre el adulterio en el contexto de algunos dichos (perennidad de la ley) en controversia con los fariseos: "Todo el que repudia a su mujer y se casa con otra, comete adulterio; y el que se casa con una repudiada por su marido, comete adulterio" (Lc 16,18). En el contexto de la redacción lucana, sigue la parábola del rico y el pobre Lázaro. De todos modos, el dicho en Lucas sigue la lógica que encontramos en Mt 5,31-32, menos la excepción que se hace con motivo de la unión ilegítima (en caso de fornicación).

Hasta aquí podemos observar que los temas del matrimonio, repudio y del adulterio están presentes en la tradición sinóptica, $y$, por consiguiente, reflejan una temática común también a la comunidad naciente. Además, en la estructura típica del paradigma o apotegma de Mateo aparece un problema que se resuelve por medio de la enseñanza de Jesús, adaptado a las particulares circunstancias de la comunidad a la cual se dirige el Evangelio.

\section{Análisis de los textos}

Después de estas consideraciones ofrecemos a continuación un análisis de los textos (de Mc y de Mt), a partir de la controversia del matrimonio y el repudio, para luego detenernos en la adición de Mateo sobre los eunucos. Por último, proponemos algunos puntos de reflexión sobre el tema del celibato.

La controversia se presenta en Judea, al otro lado del Jordán; y este lugar nos trae a la memoria el evento del paso del pueblo de Israel por el río Jordán, y, por consiguiente, nos sugiere que hay también un paso de la ley de Moisés a las enseñanzas de Jesús (Mc), o también, a las acciones milagrosas de Jesús (Mt). Los fariseos, observantes de la tradición de ley, quieren poner a prueba a Jesús y comienzan la controversia con una pregunta: “¿Puede el marido repudiar a la mujer?” (en Mc), o: “ ¿Es lícito a un hombre repudiar a su mujer por cualquier motivo?" (en Mt). Marcos emplea la pa-

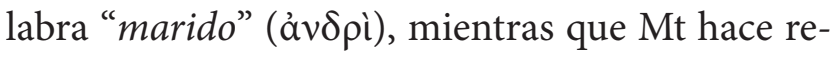
ferencia a "cualquier hombre" (ảv $\theta \rho \omega ́ \pi \omega)$ ) es decir, Mc se refiere a una condición de esposos, hecho realizado (matrimonio), mientras que para $\mathrm{Mt}$ es más general, vale para cualquier hombre, sea que pretenda contraer matrimonio o que se haya casado. Es decir, en Mt la pregunta está centrada en el hombre, pues es él quien puede ejercer el derecho de repudiar por cualquier motivo, mientras que la situación es bien distinta y difícil para la mujer. En cambio, en el evangelio de Marcos, se abre también la posibilidad del repudio para la mujer: " $y s i$ ella repudia a su marido y se casa con otro, comete adulterio" (Mc 10,12).

Con respecto a la causa del repudio había distintas posiciones de acuerdo con las escuelas más famosas de la época: la de Hillel y la de Shamai. "La escuela de Shamai dice: Un hombre no puede divorciarse de su mujer a no ser que encuentre incastidad en ella, como está escrito, porque él ha encontrado en ella indecencia en algo (Dt 24, 1a). Y la escuela de Hilel dice: (Él puede divorciarse de ella) inclusive si ella ha roto un plato, como está escrito, a causa de que él encontró indecencia en algo..." (Herron, 1982, p. 273). En otras palabras:

La permisividad del divorcio estaba asumida y el debate subsecuente estaba constituido por el significado de "algo indecente" (Dt 24,1). Como una fuente primaria, se indica el punto de vista Shamaita para el cual esta expresión refería a infidelidad; mientras que el punto de vista Hillelita se refería a la intención de incluir no solamente faltas morales, sino prácticamente cualquier cosa que el esposo encontrara molesto o embarazoso. (Herron, 1982, p. 274)

La respuesta de Jesús, como sucede frecuentemente en los evangelios, no es cerrada, sino que deja espacio para la reflexión: ¿No habéis leído 
que el Creador, desde el comienzo, los hizo varón y hembra, y que dijo: ¿Por eso dejará el hombre a su padre y a su madre y se unirá a su mujer, y los dos se harán una sola carne? De manera que ya no son dos, sino una sola carne. Pues bien, lo que Dios unió no lo separe el hombre (Mt 19,4-6).

Como hemos observado antes, el orden del discurso cambia en Mt: aquí Jesús mismo hace referencia a los orígenes; él cita la Escritura (Gn 1,27; $2,24 ; 5,2)$ identificando a Dios como el creador del varón y la hembra, justamente desde el principio (ảr 'à $\rho \chi \tilde{\eta} \varsigma)$. De esta manera, confiere autoridad a lo que sigue: la unión del macho y la hembra es voluntad de Dios, y por tal motivo, el hombre no los puede separar. En otras palabras, no existe ninguna concesión por parte del Creador y si apareciera alguna, ésta sería atribuida a los hombres.

La expresión "macho y hembra los creó" que encontramos en el primer relato de la creación (Gn 1,27) ha sido interpretada por Filón de Alejandría, y algunos rabinos, como la creación de un hombre de naturaleza andrógina. En este sentido, el segundo relato de la creación ofrece la separación de los dos géneros ( $\mathrm{Gn}$ 2,21-23) que tienden a unirse por naturaleza (Gn 2,24), y a formar uno solo como en Gn 1,27. Por tanto, Gn 2,24 no se podría interpretar como unión sexual, sino como una unión natural (Gundry, 1992, p. 531-532). Además, Luz (2003) cita a Filón de Alejandría quien explica que son "como dos mitades de un ser. Que Pablo en 1Cor 6,16 y el autor de Ef 5,31 relacionen la cita, indirecta o directamente, con el cuerpo cósmico de Cristo, indica también que se afirma la unión real con una nueva totalidad" ( $\mathrm{p}$. 131-132, n. 28). Y en esta misma línea, Luz (2003) dice: "La mujer y el hombre se pertenecen tan estrechamente porque sólo juntos forman el ser humano en el sentido pleno de la palabra" (p. 131). Por su parte, Lona (2008) articula esta unidad con los nombres hebreos ish e isha (varón y varona) y en este sentido afirma:
El hombre y la mujer forman una unidad, se pertenecen mutuamente. La afirmación cumple una función etiológica con respecto al origen del nombre isha, pero también explicativa con respecto al origen de la mujer. La unidad entre el varón y la mujer será subrayada en Gn 2,24 , en la forma de una conclusión de lo dicho sobre el origen de la mujer...El hombre está llamado a dejar el ámbito de relación al que debe su origen, para abrirse a un nuevo ámbito en el que forma con su mujer una nueva unidad. La expresión una sola carne quiere decir que el hombre forma con su mujer un solo cuerpo, aludiendo a la unión sexual. (p. 18)

Pero desde nuestro punto de vista cuando se habla de una sola carne, se quiere ir más allá; se trata de la realidad existencial, histórica, social del hombre. Una sola carne quiere decir compartir la existencia, porque somos carne, es decir, existencia.

En definitiva, y resumiendo lo anterior, se puede afirmar que el hombre no tiene la prerrogativa de repudiar unilateralmente a la esposa con la cual se ha unido mediante una alianza matrimonial (v.6b). Y, además, conviene recordar que todo el argumento hace referencia a la interpretación de la ley: la licitud ( $\check{\xi} \xi \varepsilon \sigma \tau$ เ Mt 19,3) del repudio por cualquier causa; por el mandamiento de Moisés que obliga a la firma del "libelo de repudio" antes de la separación efectiva. En efecto, esta ley se interpreta a favor del esposo y Jesús quiere evitarlo. Por otra parte, el texto muy seguramente ha tenido un proceso redaccional que explica el hecho de que existan dos respuestas (vv. 4-5) a la pregunta (v. 3). La primera que hace referencia al orden del relato original (v.4) y la segunda al propósito original de

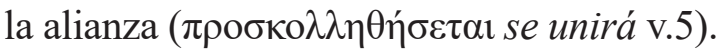

Así continúa el diálogo por parte de los fariseos: “¿Por qué Moisés prescribió dar acta de repudio y repudiarla?” (Mt 19,7). Aquí la ley en discusión es la del repudio, hecha por los hombres, 
mientras que la enseñanza de Jesús se remonta a los orígenes, es decir, a la voluntad de Dios. Se subraya, de este modo, cuanto se ha dicho anteriormente, sea por $\mathrm{Mc}$ o por $\mathrm{Mt}$, en la controversia con los fariseos: "Dejando el precepto de Dios, os aferráis a la tradición de los hombres" (Mc 7,8; Mt 15,2-4). Se cambian los verbos en una y otra tradición; mientras en Mc los fariseos hablan de la concesión de Moisés, y Jesús habla del precepto, en Mt es todo lo contrario: los fariseos hablan del precepto y Jesús de la concesión. De todos modos, se hace referencia al libro del Deuteronomio, donde la mujer pasaba de marido en marido a causa del repudio del uno o del otro, y el marido, o los maridos precedentes, no podían tomarla de nuevo en segundas nupcias. El texto dice exactamente lo siguiente:

Si un hombre toma una mujer y se casa con ella, y resulta que esta mujer no halla gracia a sus ojos, porque descubre en ella algo que le desagrada, le redactará un libelo de repudio, se lo pondrá en su mano y la despedirá de su casa. Si después de salir y marcharse de casa de éste, se casa con otro hombre, y luego este otro hombre le cobra aversión, le redacta un libelo de repudio, lo pone en su mano y la despide de su casa (Dt 24,1-3).

Pero enseguida Jesús responde y explica la causa de este precepto: "Moisés, teniendo en cuenta la dureza de vuestro corazón, os permitió repudiar a vuestras mujeres; pero al principio no fue asi" (Mt 19,8). En otras palabras, existe una ley desde el principio de la creación que está por encima de Moisés y de su Torah, y es esta ley la que sigue Jesús. Moisés ha tenido que dar posteriormente

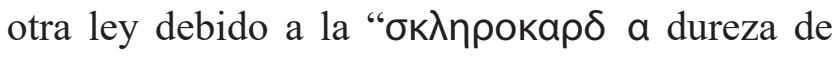
corazón". Para Luz (2003) esta es una expresión bíblica de carácter sapiencial que hace referencia, en general, al aspecto interno del pecado, sobre todo contra Dios: falta de disposición a la conversión, resistencia a Dios, contumacia (p. 132). Ciertamente el corazón del hombre en la tradición bíblica tiene varias acepciones tanto positivas como negativas. En efecto, por una parte, es la sede del pensamiento y del sentimiento, pero, por otra, allí se almacena la maldad del hombre (cf. Gn 6,5-6; 8,21; Jr 17,9). Jesús mismo afirma que desde dentro del corazón del hombre proceden una serie de maldades que contaminan al hombre (Mc 7,21-23; Mt 15,18; ver también Ex 4; 7,1322; 8,15; Jos 11,20; Is 6,9; Hb 3,8-15; Hch 7,15; Rm 11,25). Desde esta perspectiva, Jesús se propone un objetivo pastoral bien preciso: trasformar el corazón del hombre.

Como es usual en Mc, después del diálogo en público, Jesús explica a sus discípulos en casa: "Él les dijo: Quien repudie a su mujer y se case con otra, comete adulterio contra aquélla; y si ella repudia a su marido y se casa con otro, comete adulterio" (Mc 10,11-12). El adulterio estaba prohibido según la ley: "No cometerás adulterio... ni codiciarás la mujer de tu prójimo..." (Ex 20,14.17). "Si se sorprende a un hombre acostado con una mujer casada, morirán los dos..." (Dt 22,22; cf. Ex 22,15-16; Dt 22,28-29; Sir 41,22-24; Pro 23,26-28; 29,3; Lv 19,29; 21,7.9; Gn 34,31; Dt 23,18-19). Ahora bien, es propio de Mc permitir que la mujer también pueda dejar a su marido, tal vez nos encontramos en un contexto romano donde ella podía ejercer este derecho (Gundry, 1992 p. 532-533). O tal vez, asistimos a una forma de mentalidad igualitaria que se anclaría perfectamente al libro del Génesis, donde se dice que el hombre y la mujer han sido creados a imagen y semejanza de Dios (Gn 1,27). Esta expresión "imagen y semejanza" significa que toda la humanidad es igual frente a su Creador, y, por tanto, no puede haber ninguna discriminación entre los seres humanos, ni de orden social, ni de orden racial, ni sexual, etc. (Ska, 2008, p. 22). 
Pero esta indiscriminación parece no ser tan evidente en el contexto judío (Mateo). En efecto, Jesús explica la causa de la concesión dada por Moisés y hace referencia por segunda vez "al

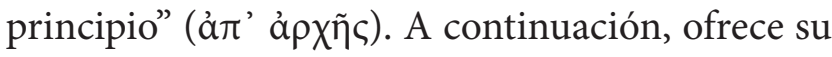
enseñanza: "Os digo que quien repudie a su mujer - no por fornicación - y se case con otra, comete adulterio" (Mt 19, 9). Mateo agrega a la tradición marcana la excepción en el caso de "fornicación",

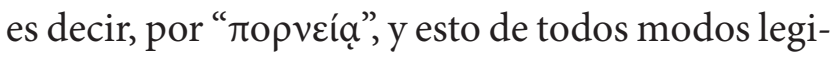
tima el repudio, o al menos, deja la puerta abierta. Ahora bien, la expresión ropveía hace referencia a cualquier forma de comportamiento sexual incorrecto por parte de la mujer, sobre todo, el adulterio (Luz, 2003, p. 136). En este caso, estaba permitido repudiar a la mujer, y en caso de que no funcionara el matrimonio, era mejor permanecer separado y no dar espacio a segundas nupcias; y esto era válido también para la mujer (Jerónimo, 1999, p. 205).

En otras palabras, además de la esclerocardía podría haber otras causas, no solamente jurídicas, sino también de orden moral, que salían del corazón con maldad. Por ejemplo, la dote; tal vez Moisés se daba cuenta que el acta de repudio se hacía para tener una segunda mujer que fuera más rica, más joven o más hermosa; probablemente le hacían la vida imposible a la primera, incluso hasta provocarle la muerte. Entonces, Moisés prefiere permitir la separación antes de que progrese el odio y luego el homicidio. Pero en todo caso, aquí se trata de la decisión de un hombre (Moisés), pero no de Dios (Jerónimo, 1999, p. 204-205). Se puede observar también que había una usual praxis de divorcio liberal, y se discutía sobre los motivos de la separación (Gnilka, 2001, p. 88).

De todos modos, la excepción "por fornicación” no es de fácil comprensión: ¿Significará entonces, que el marido, en el caso de unión ilegal de la propia mujer, pueda renunciar a permanecer en matrimonio o que deba repudiarla? En este caso, el repudio no sería una obligación, porque se puede también renunciar a éste. Por ejemplo, Mt 1,18-25 indica que el justo José repudió a María en secreto. Sin embargo, José para renunciar al repudio, según Mateo, tuvo necesidad de la intervención de un ángel (Luz, 2003, p. 136-137). En nuestro texto pareciera que se trata de la segunda posibilidad, es decir, que el marido tendría que repudiar a la mujer en caso de fornicación. Y, además, cabe la pregunta de si la excepción se refiere solamente a la primera parte del mandato de Jesús, el repudio, o también a la segunda parte, las nuevas nupcias. Porque la lectura ad litteram del v.9 no permite dar alguna respuesta excluyente. Por tanto, se da cabida a las dos interpretaciones (Luz, 2003, p. 136-137).

Al relacionar Mt 5,32 con Mt 19, 11-12, se observa cómo en ambos casos, la mujer separada del marido no tiene libertad para volverse a casar, por cuanto delante de Dios su matrimonio todavía está vigente; del mismo modo, el marido separado, a los ojos de Dios, tampoco es libre para volverse a casar (Ognibeni, 2009, p. 136-137). Ognibeni (2009), se expresa así: "Jesús no solo quita al hombre el derecho de tomar una mujer divorciada, sino también el derecho de divorciarse a su vez y tomar otra mujer en remplazo de la primera" (p. 137).

Este último aspecto está claro para la tradición marcana (tradición más antigua). Aquí no hay lugar a excepciones: Dios es contrario a la acción del hombre de disolver aquello que Él mismo ha unido. Y Jesús debe aclarar esta voluntad de Dios por medio de su enseñanza. También en la comunidad de Mateo, no obstante, la introducción de la

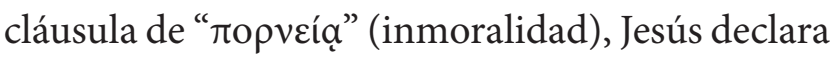
el repudio radicalmente contrario a Dios, por tanto, Él defiende el matrimonio único, como ha sido creado desde el principio. Mateo y su comunidad no anulan este principio de Jesús; simplemente establecen que existe un caso en el cual el hombre no puede permanecer en el matrimonio: en caso 
de inmoralidad o adulterio de la mujer (Luz, 2003, p. 138). En otras palabras, Jesús establece que el pecado de adulterio es cometido sin importar si es el esposo quien se divorcia de la esposa o la esposa quien se divorcia del esposo. Así, se concluye que no importa nuestra posición con respecto a esta cláusula excepcional, la enseñanza de Jesús sobre el divorcio y las nuevas nupcias aplica igualmente a ambos, a hombres y a mujeres, a pesar de que los hombres sean el foco en Mateo (Jones, 2002, p. 45).

Tomando ahora en consideración la reacción de los discípulos: "Si tal es la condición del hombre respecto de su mujer, no conviene casarse" (19,1012). Jesús ahora cambia de interlocutores: se nota una participación activa de los discípulos sobre el argumento que anteriormente se desarrollaba con los fariseos. La perplejidad de los discípulos está en conexión con la situación del hombre respecto a la mujer, no de modo general, sino en el contexto matrimonial, es decir, la situación del marido con la mujer "o del hombre casado" (Ognibeni, 2009, p. 134). Como dice Konkel (2005), la respuesta de los discípulos a la enseñanza de Jesús divide a los académicos: ¿Los versículos 11 y 12 son la respuesta de Jesús al comentario de los discípulos o es una continuidad de la instrucción de Jesús sobre el matrimonio de los versículos 4-9? Si en el versículo 11 Jesús continúa su instrucción sobre el matrimonio (v 9), entonces Él está dando una instrucción especial a sus discípulos de no volverse a casar después del divorcio. Los indisolubilistas retienen que en el v. 9 Jesús declara que el matrimonio es una unión permanente, en el v 10 los discípulos reaccionan con incredulidad al pensamiento de una vida de soltería -aparte de la relación marital-: si un hombre no puede salirse del matrimonio y casarse con otra, entonces es mejor no casarse. (p. 31).

Ahora bien, si "la causa" (aíía) se refiere al motivo del repudio, que en este caso es el adul-

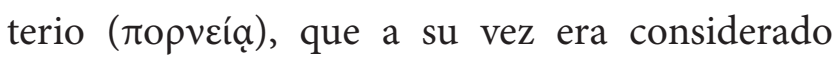

como un pecado: "Tampoco yo te condeno. Vete, $y$ en adelante no peques más" (Jn 8, 11); entonces los discípulos están haciendo un juicio extremamente severo, como si el matrimonio dejara de ser ventajoso. Pero la intervención de los discípulos no debe ser considerada como impertinente, sino que ellos ponen una pregunta con un alto sentido y contenido teológico, puesto que el matrimonio ha sido establecido por Dios, y, por esta razón, no puede ser desfavorable. Quien lo hace desfavorable es quien se separa para luego volverse a casar (Mt 5,32) (Ognibeni, 2009, p. 134).

Según Dt 24,1-4 el documento de repudio contenía la autorización del marido con el fin de que la mujer pudiera volver a contraer nupcias; por tanto, el marido se hacía cómplice del futuro adulterio. Además, el hombre que se casa con esta mujer, comete adulterio (Mt 5,32). Pero que lo haga con el consentimiento escrito de su primer marido no cuenta para nada, porque a los ojos de Dios, ella permanece casada; cualquier cosa que haya declarado el marido en el documento de repudio no es otra cosa que palabra humana, que no puede tener la pretensión de anular la palabra divina. De este modo, Jesús no solo quita al hombre el derecho de tomar como mujer a una repudiada, sino también el derecho de repudiar y tomar otra mujer en cambio de la primera. Y a propósito de esta "otra", se aclara que no quiere decir que haya sido divorciada. Si es libre, tenemos una importante extensión del relato de adulterio, que ya no está limitado a la mera unión con la mujer de otro, como había sido concebido por toda la legislación del Antiguo Testamento. Una mujer cometía adulterio andando con cualquier hombre que no fuera su esposo; un marido en cambio, solo con la mujer de otro. Son dos situaciones jurídicas bien diferentes, que Jesús las equipara (Ognibeni, 2009, p. 136-137).

Ahora Jesús responde a sus discípulos: "No todos entienden este lenguaje, sino aquellos a quienes se les ha concedido" (Mt 19, 11). Este versículo 
contiene un pasivo divino, que da a entender cómo el mandamiento aplicado a todos los hombres tendrá que ser acogido solamente por aquellos a los cuales ha sido concedido por Dios. En otras palabras, el objeto de la concesión mosaica consiste en la capacidad de "acoger" ( $\chi \omega \rho \varepsilon ́ \omega)$ "esta palabra"; no se trata de una comprensión intelectual, sino, sobre todo, de escucha, aceptación y acogida; como se entiende en Jn 8, 37: “... mi palabra no tiene acogida ( $\chi \omega \rho \varepsilon ́ \omega)$ en vosotros" (Ognibeni, 2009, p. 139).

Ante la pregunta si "esta palabra" (入óyos oṽ்o) hace referencia a lo que precede o a lo que sigue. Es decir, se refiere al repudio para volverse a casar, o a la sentencia de Jesús sobre los eunucos. Las opiniones están de una y otra parte. Para Ognibeni, 2009, p.139 "esta palabra" hace referencia a lo que precede; y en esta misma línea está también Malina \& Rohrbaugh (1996), quienes hacen un estudio antropológico y social de esta perícopa, afirmando que el logion se refiere a lo que precede: "lo que estaba prohibido en la comunidad de Mateo era divorciarse y volverse a casar" (p. 97). Por el contrario, Luz, 2003, sostiene que el dicho hace referencia a aquello que sigue, es decir, a los eunucos (p. 147-148). Pero bien sea que se refiera a lo que precede o a lo que sigue, hay algo que debe quedar bien claro: Se trata de una palabra que solo Dios concede de ser acogida dentro de sí, y no puede ser una mera palabra humana. Si aceptamos que el dicho se refiere a lo que sigue, estamos de acuerdo con Blomberg, 1990, cuando dice que Jesús implícitamente respalda la objeción de los discípulos y estaría afirmando que no todos son capaces de abstenerse de matrimonio, sino sólo aquellos a los cuales Dios particularmente concede. El pasivo divino denota algo que es dado, y en este sentido, respaldaría la convicción tradicional del catolicismo romano, en la cual la posibilidad de vivir una vida celibataria está también disponible para quienquiera que la pida (p. 183).

Es necesario recordar que Jesús había dicho a los fariseos que la causa por la cual Moisés había

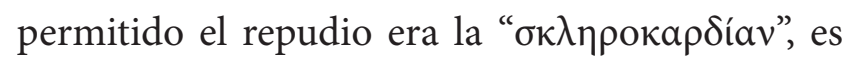
decir, la imposibilidad para hacer la voluntad de Dios; pero, por el contrario, habrá algunos que tienen un corazón dócil y que acogen la palabra (Mc 4,3-9; Mt 13,3-9; Lc 8,4-8; ver especialmente Mt 13,11-12): para ellos el matrimonio no es para nada desfavorable (Ognibeni, 2009, p.140). Aquí también es importante resaltar que la inclu-

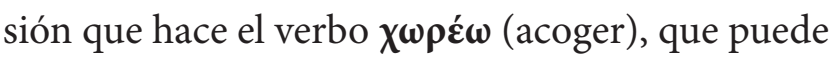
indicar tanto el final de la enseñanza precedente (v. 10 no conviene casarse), como el final del v. 12 (sobre los eunucos). De todos modos, la caracterización del eunuco deja espacio a una condición permitida al interior de la comunidad con una finalidad específica, es decir, al servicio del reino de los cielos o "por el reino de los cielos". Y creemos que este es punto nodal del texto: ahora hay otra opción de vida avalada por Jesús, la vida celibataria, que se convierte en una muy buena alternativa a una vida matrimonial irregular.

En este sentido, hay acuerdo con Blomberg (1990) en que la mayor adición a la perícopa de Mateo son los vv. 10 al 12. Como en otras partes, él está particularmente preocupado por las implicaciones de la enseñanza de Jesús para el discipulado. Los doce reconocen que la posición de Jesús es mucho más estricta que aquélla de sus contemporáneos; ellos revisan la idea y especulan sobre si el celibato sería la opción preferible, -al menos en el sentido de ser más manejable-. Sin duda, más de un cónyuge en la historia del mundo con frecuencia habrá reflexionado sobre si no habría sido mejor estar solo que "atrapado" en un matrimonio aparentemente insoportable (p. 182-183).

Jesús confirma cuanto ha enseñado hasta el momento ( $\gamma$ à $\rho)$ con el dicho sobre los eunucos: Porque hay eunucos que así nacieron desde el seno de su madre, y hay eunucos que fueron hechos eunucos por los hombres, y también hay 
eunucos que a sí mismos se hicieron eunucos por causa del reino de los cielos. El que pueda aceptar esto, que lo acepte (Mt 19, 12).

En el diccionario italiano "Treccani" encontramos la siguiente definición de eunuco: "del lat.

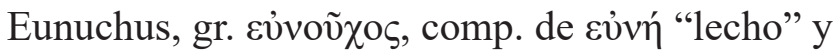
$\varepsilon \varkappa \chi \omega$ en el sentido de "custodiar", propr. "custodio del lecho”. En el significado más común, hombre privado de la facultad viril, o por defecto orgánico o después de eviración...". Según la Sagrada Escritura la eviración estaba absolutamente prohibida; los eunucos eran expulsados de la comunidad litúrgica (asamblea del Señor, cf. Dt 23,2-4), así como los "bastardos" (Dt 23,2), los amonitas y los moabitas; éstos últimos en cuanto se habían comportado mal con el pueblo de Israel durante la travesía por el desierto (Dt 23,3ss). Por su parte, Malina \& Rohrbaugh (1996), dicen que ser eunuco en la cultura judía era un deshonor (p. 98).

Existe una congruencia entre la frase de los discípulos y la frase de Jesús sobre las tres especies de eunucos. Mientras los discípulos han hablado del hombre casado, Jesús cita el ejemplo perfectamente antitético del eunuco. La anotación es pertinente porque los discípulos habían dicho que no era favorable casarse, el eunuco es, en efecto, un hombre para el cual el matrimonio no tiene ninguna ventaja: ¿para qué tener una mujer? El eunuco, más precisamente el eunuco voluntario, se utiliza como un parámetro con el cual se confronta al hombre que ha tomado mujer (Ognibeni, 2009, p. 140).

Según el dicho de Jesús, existen dos clases de eunucos que lo son de manera involuntaria, y una tercera clase que lo es voluntariamente, y esta última con el objetivo de entrar en el reino de los cielos. Se trata, sin lugar a dudas, de una hipérbole, muy similar a aquella en la cual Jesús invita a sacarse un ojo o a amputarse una mano con tal de entrar en el reino de los cielos (Ognibeni, 2009, p. 141).

Con respecto al ambiente vital del dicho de
Jesús, Ognibeni, 2009, se pregunta, y formula la hipótesis, sobre quiénes son esta clase de eunucos: tal vez los sacerdotes del culto de Cibeles (la diosa Frigia que era venerada en aquel tiempo en toda el área mediterránea, y tal vez, incluso en Palestina) (p. 142). Por otra parte, Talbott (2006), examinando el término "eunuco" en el evangelio de Mateo y en el contexto del antiguo mundo mediterráneo, concluye que la respuesta de Jesús desafía el poder masculino tradicional enraizado en el señor de la casa y el matrimonio kiriárkico (neologismo para patriarcal, señorial), donde las estructuras kiriárkicas determinan roles de género y los eunucos no simbolizan a ninguno de los dos: ni hombre ni mujer. El autor sostiene que el llamado de Jesús a los hombres para hacerse a sí mismo eunucos por el reino de los cielos, desafió el poder masculino y ayudó a redefinir roles sociales para las mujeres en el movimiento de Jesús. La conservación de este difícil dicho, sugiere que las comunidades mateanas luchaban por unas relaciones ideales machohembra en el reino promulgado por Jesús (p. 22). Y en otro apartado de su artículo, Talbott, 2006, dice que, en el evangelio de Mateo, Jesús no solamente se aleja de las características kirialcales de los "amos de casa" sino que los desafía con un modelo alternativo. Esta separación no involucraba una total emasculación de la cultura mediterránea antigua. Después de todo, el Jesús Mateano se refiere a Dios como "Padre" y Mateo llama a Jesús: Señor e Hijo de Dios. Esta inferencia sirve para recordar que Jesús y el movimiento que el inspiró desde Galilea y Siria, fue parte de dos complejas culturas: judía-helenística. La pregunta crucial en la reconstrucción histórica de Jesús es, si tuvo lugar un sincretismo entre ambas culturas o cuál modelo influyó más la vida y las enseñanzas de Jesús: una cultura tradicional israelita o la romanohelenística (p. 25). En cambio, para Beinert (1989) se trataría de una apología de Jesús mismo contra sus contemporáneos que se burlaban de él y de sus 
discípulos porque andaban por el país sin mujer (p. 140).

Sea cual sea el contexto antropológico-cultural, y continuando con nuestro estudio del texto, notamos que Jesús cita el caso de los eunucos voluntarios para confirmar su enseñanza sobre la prohibición de repudiar y de volverse a casar. Puesto que por el hecho de que existan hombres que voluntariamente han decidido volverse eunucos, no significa que el matrimonio no sea importante, o que sea desfavorable, sino que, con la ayuda de Dios es posible no contraerlo. De todos modos:

El diálogo entre Jesús y sus discípulos no versa sobre el matrimonio en abstracto, sino sobre el matrimonio sucesivo al divorcio, es decir, sobre la unión con una mujer distinta de la legítima. De un tal matrimonio se puede prescindir, y no se puede objetar que tal sacrificio esté por encima de las posibilidades humanas, porque es un hecho documentado que a algunos Dios concede la capacidad para prescindir del matrimonio" (Ognibeni, 2009, p. 142).

En este caso, como dice Luz, 2003, metafóricamente eunuco significaría la opción por el celibato o por la ascesis sexual (p. 153).

En otras palabras, por el reino de Dios se puede prescindir del matrimonio, y vale la pena hacerlo. Ningún sacrificio es tan grande o difícil con tal de entrar en el reino de los cielos. Ahora bien, quien pueda acoger esta palabra que la acoja. El verbo $\chi \omega \rho \varepsilon ́ \omega$ (acoger), en imperativo presente, indica que Jesús no exige un singular acto de acogida de su Palabra sino una actitud permanente: "Aquel que ha recibido el don que lo utilice; el don divino no puede ser desperdiciado. No es una exhortación, sino una orden. Los dones de Dios están cargados de responsabilidad para quienes los reciben" (Ognibeni, 2009, p. 143). Y, por otra parte, como afirma San Pablo: "los dones y la llamada de Dios son irrevocables" $(\mathrm{Rm} 11,29)$.

\section{Relación del texto con el contexto de los evangelios}

Al comparar las dos tradiciones del texto, se observa que Mateo sigue a Marcos muy de cerca. Ahora bien, en ambos Evangelios, Jesús se refiere a la salvación del hombre, afirmando que: "nada es imposible a Dios" (Mc 10,27; Mt 19,25-26; cf. Lc 18,27). Dado que el contexto general aquí es el de la riqueza, según Ognibeni, 2009, Mt 19 se presenta como una catequesis donde se pide una doble renuncia tanto a la vida matrimonial como a la riqueza; $y$ que se pide a quien quiera entrar en el reino de los cielos (p. 144). Nosotros consideramos, junto con Luz (2003) que no se trata de una renuncia a la vida matrimonial para entrar en el reino de los cielos, sino de contraer unas segundas nupcias como se ha dicho hasta ahora. Se puede también verificar que Jesús no fundamentó la prohibición del repudio en la prospectiva del reino de los cielos, sino en el principio, es decir, desde la creación (p. 151).

Por otra parte, en el contexto de los dos Evangelios, también se hace referencia a los niños dentro del mismo campo semántico: matrimonio-niños. Como dice Ognibeni (2009), quien renuncia a la mujer también renuncia a los niños, aún más, hacerse niño para entrar al reino de los cielos es metafóricamente similar a hacerse eunuco por el reino de los cielos. En efecto, ni el niño ni el eunuco tienen la capacidad de engendrar hijos; $y$, además, así como el niño depende totalmente de sus padres, así también, el eunuco dependerá totalmente de Dios, deberá confiar totalmente en Él, sin esperar alguna recompensa (p. 146).

Además, se nota que, en la recompensa a las renuncias hechas por los discípulos, ni Marcos, ni tampoco Mateo mencionan a las mujeres (Mc 10,30; Mt 19,29). En cambio, Lucas es explícito: "Entonces Él les dijo: En verdad os digo: no hay nadie que haya dejado casa, o mujer, o hermanos, o 
padres o hijos por la causa del reino de Dios, que no reciba muchas veces más en este tiempo, y en el siglo venidero, la vida eterna" (Lc 18, 29 - 30). Pero también en Lucas se lee "Si alguno viene donde mí y no odia a su padre, a su madre, a su mujer, a sus hijos, a sus hermanos, a sus hermanas y hasta su propia vida, no puede ser discípulo mío" (Lc 14, 26).

Una de las características principales del texto de Mateo es que es androcéntrico. En efecto, solamente el hombre puede tomar la decisión de repudiar a la mujer. En este mismo sentido, Jesús habla de los eunucos, que pueden serlo solamente los hombres. Ognibeni (2009), toma posición en defensa de la mujer sosteniendo que "en la sociedad de aquel lugar y de aquel tiempo, una halaha antidivorcista protegía más a la mujer que al hombre. Además, se puede asegurar que Jesús no pedía solo a los hombres la disponibilidad para renunciar a la vida matrimonial” (p. 145). Ciertamente Jesús tenía mujeres que lo seguían como discípulas (Juana, Susana y muchas otras cf. Lc 8,3) y en la lógica del repudio Él no podía aceptar que se tratase a la mujer como un objeto que se descarta, o que se cambia, una por otra.

Por otro lado, el matrimonio es una realidad que pertenece solo a este mundo, porque: "cuando resuciten de entre los muertos, ni ellos tomarán mujer ni ellas marido, sino que serán como ángeles en los cielos" (Mc 12, 25). Entonces, renunciar al matrimonio por el reino de los cielos, quiere decir comenzar y degustar la eternidad desde este mundo. Como dice el gran teólogo, el cardenal Lubac (1993): "El hombre vale absolutamente porque su rostro está iluminado por un rayo del rostro divino; porque, a la vez que se va desarrollando y obrando en la historia, ya respira en la eternidad" (p. 144).

\section{Actualidad del texto}

Se registra hoy en el mundo un incremento considerable de la praxis de la separación matrimonial.
Según Luz (2003), la praxis católica, que niega el divorcio, es aquella más afín con lo que encontramos en el evangelio de Mateo. Este autor sostiene que la praxis protestante está bastante lejos de este ideal porque en ella "parece no haber límite alguno para las bodas eclesiásticas repetidas" (p. 140). De todos modos, la práctica matrimonial hoy, es bastante diversa de la de la época de Jesús; porque ya no existen matrimonios organizados por las familias, sino por los jóvenes con un sentido romántico. Además, ya no existen familias con muchos componentes reunidos en un sentido patriarcal, sino familias numéricamente pequeñas y aisladas. "La historia de la época moderna, es una historia de individualización progresiva que no podemos ni debemos frenar" (Luz, 2003, p. 140-141).

A diferencia de la severidad de la ley en el A.T., el relato de Juan 8 demuestra que Jesús perdona a la mujer adúltera, ofreciéndole la gracia y la misericordia de las cuales Él es el portador. Es decir, hay esperanza y reivindicación para una persona que ha caído en adulterio; el perdón y la reconciliación están por encima del acta de repudio establecida por la ley mosaica.

Dentro de esta perspectiva de perdón y de misericordia escribe Pikaza, 2013:

En la base del matrimonio cristiano sigue estando la fidelidad de Jesús hacia los marginados... si los cristianos lo olvidaran construyendo una iglesia sectaria donde solo entran los puros, $y$ convirtiendo el matrimonio 'legalmente establecido y celebrado' en criterio de admisión eclesial, correrían el peligro de perder su identidad mesiánica. El matrimonio mesiánico solo se puede entender allí donde la iglesia acoge a los excluidos de la sociedad (y de un modo especial a los que rompen o no pueden cumplir la legalidad formal del matrimonio). Esto significa que, leído en su conjunto, Marcos abre la puerta cristiana para aquellos que hoy tendrían 
'problemas matrimoniales' (impedidos de diverso tipo, prostitutos/as, divorciados, homosexuales, etc.). (p. 703)

Siguiendo esta misma perspectiva de inclusión, podemos decir que las palabras de Jesús, ahora más que nunca, son actuales: "Los que están sanos no tienen necesidad de médico, sino los que están enfermos; no he venido a llamar a justos, sino a pecadores" (Mc 2,17).

Con el dicho de Jesús sobre los eunucos también se actualiza para ellos la esperanza anunciada por el Profeta Isaías:

Pues así dice Yahveh: Respecto a los eunucos que guardan mis sábados y eligen aquello que me agrada y se mantienen firmes en mi alianza, yo he de darles en mi Casa y en mis muros monumento y nombre mejor que hijos e hijas; nombre eterno les daré que no será borrado (Is 56, 4-5).

Pero recordemos que, en la iglesia antigua, por lo general, no se mencionaba a los eunucos por el riesgo de seguir este pasaje ad litteram (Los eunucos no podían llegar a ser sacerdotes, según lo dicho en la tradición bíblica y en el Código de Derecho Canónico: Lev 21,20s; Dt 23,1, CIC can 1041 n. 5). Según Luz (2003), en la nota 79 , dice que no solamente Orígenes, sino que había muchos casos de eviración por causa de este texto (p. 144). Este autor afirma que incluso por la búsqueda de una ascesis exagerada; pero también, ejerciendo la propia libertad: "Porque un verdadero eunuco no es, según Clemente de Alejandría, el incapaz de ejercer la actividad sexual, sino el que no quiere ejercerla" (p. 145). Sin embargo, el texto tuvo mucho éxito en la época de la Reforma cuando se desarrolló la polémica sobre los votos religiosos y el celibato. Y continúa Luz (2003), diciendo que con la Reforma se comprende que el tercer tipo de eunucos se debe interpretar con sentido alegórico o figurativo (ascesis sexual). Sobre todo, en la exégesis griega, donde había eunucos naturales (buenos por naturaleza); los evirados por los hombres, que son aquellos que se dejan seducir por los falsos maestros o filósofos (pero también en un sentido positivo aquel que por medio de los maestros humanos ha llegado al conocimiento y a las obras buenas); y, finalmente, los eunucos por el reino de los cielos son aquellos que han alcanzado el conocimiento con la lectura de la Palabra de Dios. En la exégesis protestante también los casados tienen la posibilidad de evirarse espiritualmente y servir al evangelio. "La alegoría se convierte aquí en subterfugio exegético ante el texto" (p. 146).

Luz (2003), dice que los críticos eclesiásticos tienen más discreción para poner límites a la ascesis en virtud de este texto, e insisten en decir que "no todos comprenden". Otros interpretan a Mt 19,12 no como un consejo sobre la virginidad, sino como un precepto (p. $145 \mathrm{cf}$. Nota 89). Luego se entendió en sentido escatológico como un medio para alcanzar el reino de los cielos. Incluso el Concilio de Trento, a la luz de 1Cor 7 y Mt 19,12, declaró que el estado de virginidad era mejor que el del matrimonio. De todos modos, en ámbito católico se retenía que el celibato y la virginidad eran considerados como virtud, don de Dios, no conquista humana, y gustaba citar a Agustín: "Domine, da quod iubes, et iube quod vis. Iubes continentiam, da continentiam" (p. 145-147).

El texto de Mt 19,10-12 ha sido considerado por la tradición eclesial (y también por muchos exégetas) como palabra del Señor que fundamenta el celibato sacerdotal y la consagración religiosa (votos). Pero la pregunta que formulamos es la siguiente: ¿Se puede establecer el fundamento del celibato o de la virginidad a partir de Mt 19,11-12?

Creemos que una mirada al mundo antiguo y a la trayectoria bíblica será muy iluminadora antes de dar una respuesta. Mientras que en el mundo antiguo para otras religiones el celibato, concretamente 
la virginidad, era considerada como un valor o una virtud, no era así para el pueblo de Israel. Por el contrario, allí se exhorta al matrimonio fecundo (Sal 127,3-5; 128,1-3). Por otra parte, la virginidad para el pueblo de Israel era considerada como una virtud o un valor antes de contraer matrimonio (Gn 24,16; cf. Lv 21,3). Perder la virginidad antes del matrimonio era una abominación que se tenía que reparar (2Sam 3,13; Dt 22,14ss.20ss); la virginidad tenía que ser respetada (2Sam 13,2). Al sumo sacerdote se le pedía contraer matrimonio con una virgen (Lv 21,13). La pérdida de la virginidad de la hermana de Absalón fue castigada con el asesinato de Amón, el hermanastro de Absalón. En este sentido, se comprende que el valor de la virginidad antes del matrimonio era tan grande que se equiparaba al valor de la vida misma. Por otro lado, la esterilidad era considerada como un signo de maldición divina y propiciaba el desprecio (Gn 16,4; 30,1-2; 1Sam 1,5-18; Lc 1,25). El profeta Oseas lanza esta maldición simbólica contra Israel: "Dales, Yahveh..., ¿qué les darás? ¡Dales seno que aborte y pechos secos!" (Os 9,14).

De acuerdo con lo anterior, y por cuanto hemos dicho hasta ahora, y, sobre todo, con respecto al contexto de la perícopa, pareciera que no. De todos modos, las opiniones de los exégetas, como de costumbre, no concuerdan sobre este argumento. Por ejemplo, para Foresi (1979), "la interpretación celibataria aparece no solo como probable sino segura" (p. 47).

Para nosotros el problema sigue radicando en qué significa la expresión "esta palabra" (tòv

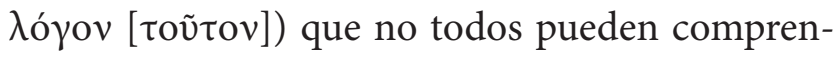
der. Tal como hemos dicho anteriormente haría referencia a aquello que precede, es decir, que no se pueden contraer segundas nupcias, o lo que es lo mismo, se refiere a la indisolubilidad del matrimonio. Pero, por otra parte, también existen los que Luz (2003), llama "los representantes de la exégesis tradicional sobre el celibato" (p. 148) (cf.
También la nota 106), quienes defienden el versículo 11 refiriéndose a lo que sigue, de tal modo que formaría un conjunto con el versículo 12a (el v.10 haría de transición). Luz (2003), afirma:

Los discípulos dicen que si la monogamia es tan estricta, más vale abstenerse. Jesús, en realidad debería irritarse ante la ingenua declaración de los discípulos, pero la pasa por alto y la utiliza como buena ocasión para pronunciar una sentencia que se corresponde poco con lo dicho en los v. 3-9 (p. 148).

Sin embargo, este autor ofrece tres razones

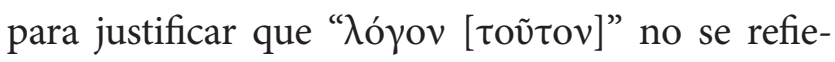

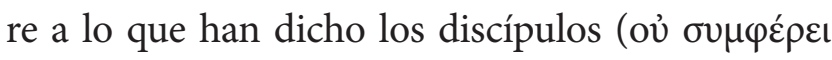

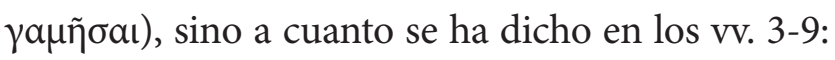
“1) en ningún otro pasaje del evangelio de Mateo valora Jesús, de ese modo, un dicho de los discípulos; porque 2) contrasta con las palabras de Jesús en los v. 3-9, que trataban del verdadero matrimonio y no del celibato, y porque 3) el dicho de los discípulos justifica la opción por la abstinencia sexual con las dificultades del matrimonio y no con el reino

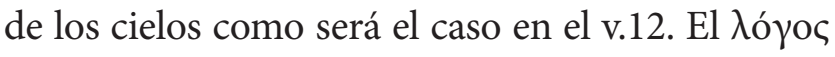
es, pues, presumiblemente el v. 9 o, en todo caso, el conjunto de los v. 3-9" (Luz, 2003, p. 149-150). En este caso, Jesús exigiría la abstinencia que después del primer matrimonio, se pide a los discípulos por el reino de los cielos (Luz, 2003, p. 150).

En definitiva, Luz (2003), llega a la conclusión que Jesús, como tampoco lo hará después San Pablo, no impuso su celibato a sus seguidores (Se podría confrontar el término "eunuco" (Mt 19,12; Act 8,27.34.36.38.39) con "agamos" (no casado 1 Cor 7,8.11.32.34). Su logion se dirige en sentido positivo a la vida de algunas personas que renunciaron al matrimonio por el reino de Dios; pero no invita a seguir esta vida (p. 154) (n. 135). Luego el mismo autor dice que el logion fue referido, por tanto, por la iglesia posterior al carisma del celibato; pero que esta exégesis no se debe apoyar sobre el evangelista Mateo. Él ha restringido la aplicación del antiguo dicho de Jesús a los separados sin 
culpa, que no pueden casarse por segunda vez. Y a la luz del dicho de Jesús se puede justificar un celibato voluntario entendido como carisma, pero no el celibato sacerdotal prescrito por la Iglesia (Luz, 2003, p. 154). A propósito, Ranche-Heinemann (2005), escribe todo un libro que habla negativamente sobre la tradición del celibato en la Iglesia, y como es obvio, no retiene el texto de Mt 19,1012 como fundamento del celibato e interpreta el logion de Jesús con referencia a los versículos 3-9.

Ahora bien, si el texto de Mateo no fundamenta el celibato, entonces tendremos que buscar otros textos $\mathrm{u}$ otra manera de argumentarlo desde el punto de vista bíblico. Por ejemplo, en la ley de Israel existe una estrecha relación entre el culto y la sexualidad, que en cierto modo acerca al concepto de celibato entendido como abstinencia sexual (Ex 19,15; 1 Sam 21,5). Pero, como tal vez esta solución no nos satisface, podemos profundizar el argumento y buscar algunas direcciones que nos puedan ayudar a entender aquello que nosotros custodiamos en la Iglesia como un tesoro. Por lo general se aborda este tema desde el punto de vista de la psicología. Un ejemplo es Guarinelli (2008) quien, en el segundo capítulo de su libro Como punto de partida, cita a Mt 19,11-12 e interpreta el celibato como un don que se da al hombre, pero todo el libro es un acercamiento al tema desde el punto de vista psicológico.

Se propone entonces fundamentar el celibato en la misma persona de Jesús. Y hacemos esta afirmación teniendo en cuenta que la revelación de Jesús va más allá de los meros textos, y que Jesús se convierte en la clave de interpretación de muchos textos de la Escritura. En otras palabras, él asume lo que es la humanidad en la historia y, por esta razón, la Escritura es el lugar donde el hombre se puede comprender a sí mismo (Jn 4). De esta manera, se enteinde que el hombre alcanza su plenitud en el encuentro con Cristo; se trata de una antropología bíblica que da principio de unidad a los dos Testamentos. Desde esta perspectiva se puede comprender mejor por qué el Magisterio de la Iglesia ratifica el celibato en continuación. $\mathrm{Al}$ respecto, son muy dicientes las palabras de Benedicto XVI, 2007, en la exhortación apostólica postsinodal Sacramentum Caritatis:

reafirmo la belleza y la importancia de una vida sacerdotal vivida en el celibato, como signo que expresa la dedicación total y exclusiva a Cristo, a la Iglesia y al Reino de Dios, y confirmo por tanto su carácter obligatorio para la tradición latina. El celibato sacerdotal, vivido con madurez, alegría y entrega, es una grandísima bendición para la Iglesia y para la sociedad misma (SC n. 24).

\section{Conclusión}

Ante todo, es importante anotar que en los textos de Marcos (10,1-10) y de Mateo (Mt 19,1-12) aparecen los dualismos: hombre-mujer, machohembra, padre-madre, esposo-mujer..., que son realidades experienciales que expresan un profundo sentido antropológico, (confrontar también el término "carne"). En esta perspectiva, se resalta que sin un marco antropológico no se pueden comprender ni el matrimonio ni el celibato (ni la vida consagrada), como tampoco se les puede reducir meramente a preceptos legales. Por el contrario, a la luz del mensaje de Jesús nos encontramos delante de una nueva interpretación de la ley que ofrece una visión prospectiva más amplia con respecto a cuanto se había establecido en la ley de Moisés

El aspecto más difícil para comprender en la elección del estado de vida en la antigüedad, es la manera como frecuentemente se entiende el matrimonio, es decir, hoy lo entendemos en una perspectiva romántica, ligada a sentimientos; pero en la antigüedad no era así: se trataba de una institución, donde la esposa aceptaba a su esposo como tal, y no tanto porque experimentara sentimientos 
hacia él. La falta de esta percepción de la costumbre matrimonial antigua puede poner límites a nuestra interpretación.

No obstante, la ley lo permita, el repudio aparece como un acto injusto a pesar de ser lícito según la ley humana. En efecto, el repudio rompe el matrimonio por cualquier razón; y Jesús no aprueba este comportamiento, aunque justifique la excepción hecha más tarde por Moisés a causa de la dureza de corazón. Jesús introduce un elemento de novedad a la tradición del matrimonio, así como es entendida hasta nuestros días. En efecto, Jesús introduce el concepto de indisolubilidad del matrimonio, es decir, hasta que la muerte de uno de los dos cónyugues rompa la alianza que fue establecida por Dios desde el principio de la creación.

Por otra parte, en el texto de Mateo se puede notar una reinterpretación de los valores. Por ejemplo, hasta aquel momento los eunucos no eran admitidos en la asamblea. Pero ahora, en la iglesia de los orígenes se incluían a los pobres, los esclavos, los enfermos y los eunucos, es decir, a la comunidad de los marginados (sobre todo por el Imperio Romano) como dice Aguirre (2011, pp. 213-240). Se pretendía formar una comunidad igualitaria, respetando las diferencias, de acuerdo con los principios evangélicos propuestos por Jesús de Nazaret. Recordemos que en la antigüedad existía una mentalidad que definía la sociedad por estratos, desde el tiempo de Esarhaddon de Asiria: "Un hombre [libre] es como la sombra de un dios. Un esclavo es como la sombra de un hombre [libre]. Pero el rey, él es similar a la imagen de Dios" (Ska, 2008, p. 18).

Con el dicho de Jesús sobre los eunucos, podemos observar, entonces, un cambio de mentalidad con respecto a la opción individual de vida de la persona: Ser eunuco (por el reino de los cielos) no es un defecto genético sino una opción personal de vida. En este sentido, Jesús, con su ejemplo, inaugura un celibato voluntario motivado por otro valor, igual o superior al matrimonio, que es el reino de los cielos. Así que el celibato tiene su fundamento en la vida de Jesús (y no necesariamente en un pasaje bíblico).

Se puede afirmar que tanto el matrimonio como el celibato son estados de vida, donde están presentes la autonomía y la libertad para expresar las propias opciones de vida; pero mientras el estado de vida matrimonial se ancla en la creación, es decir, al principio (Mc 10,6; Mt 19,8), el estado de vida célibe queda inaugurado por Jesús en la nueva perspectiva del reino de los cielos. Ahora bien, tanto el celibato como el matrimonio son opciones de vida fundamentadas en el amor, y por este motivo, ambas reclaman la fidelidad.

En los dos estados de vida, tanto matrimonio como celibato, sería muy restringido limitar su comprensión meramente desde el punto de vista de la sexualidad; esta perspectiva se debe ensanchar y ampliar a una opción de vida en y para la comunidad. En otras palabras, en una perspectiva antropológica se puede comprender el sentido de la vida y ligarlo con estas dos maneras de opciones o estados de vida. Porque más allá del tema de la sexualidad, el valor preponderante es el de la libertad individual, considerado como un acto soberano con relación a la misma persona. En efecto, la libertad y la autonomía están en la base de ambas opciones, tanto del matrimonio como del celibato; ninguna de las dos es obligatoria, ambas son donación voluntaria, entrega, renuncia a sí mismo y, por tanto, ambas reclaman la fidelidad como valor humano y moral porque ambas conducen al reino de los cielos.

\section{Referencias}

Aguirre, R. (2011) El Evangelio de Jesucristo y el Imperio Romano. Estudios Eclesiásticos, 86, (337).

Beinert, W. (1989). El Evangelio regla de vida. Barcelo- 
na: Herder

Benedicto XVI. (2007). Sacramentum caritatis. Ciudad del Vaticano. Librería Editrice Vaticana.

Blomberg, C. L. (1990). Marriage, Divorce, Remarriage and Celibacy: An exegesis of Matthew

19, 3-12. Trinity Journal 11.

Foresi, P. (1979). II celibato in Matteo Riv Nuova Umanità, N. Roma: Città Nuova

Gnilka, J. (2001). El Evangelio según San Marcos, II, 4. edición. Salamanca: Sígueme.

Guarinelli, S. (2008). Il Celibato dei preti, Perché sceglierlo ancora. Milano, San Pablo

Heinemann, U. (2005). Eunucos por el reino de los cielos. La Iglesia Católica y la sexualidad. Madrid: Trotta.

Herron, R. W. Mark's Jesus on divorce: Mark 10, 1-12 Reconsidered. Journal of the Evangelical Theological Society, 24, No. 3, September 1982.

Jerónimo., Peña, R., Bianchi. C. B., \& Suárez, M. E. (1999). Comentario al Evangelio de Mateo. Madrid: Ciudad Nueva.

Jones, B. (2002). A Biblical Theology of marriage, divor$c e$, and remarriage (Doctoral dissertation, Detroit Baptist Theological Seminary).

Konkel, M. (2005). Divorce and Remarriage. Tren Dissertations. 4814 Denver. Baptist
Seminary. Recuperado de: http://cbwc.ca/wp-content/ uploads/2013/10/Mel-Konkel-Thesis-DivorceRemarriage.pdf

Lona, H. E. (2008) ¿Qué es el hombre para que te acuerdes de él? Estudios de Antropología

Bíblica. Buenos Aires. $1^{\text {a }}$ Edición Ed Claretiana.

Lubac, H. de (1993). Por los caminos de Dios, Madrid. Ediciones Encuentro.

Luz, U. (2003). El Evangelio Según san Mateo, III, Salamanca: Sígueme

Malina, B. J., \& Rohrbaugh, R. L. (1996). Los evangelios sinópticos y la cultura mediterránea del siglo I: comentario desde las ciencias sociales. Pamplona: Verbo Divino.

Ognibeni, B. (2009). Non conviene prendere moglie (Mt 19,10): Una strana affermazione.

Marcianum, Recuperado de:http://www.istitutogp2.it/ public/non\%20conviene.pdf

Pikaza, X. (2013). Evangelio de Marcos: La buena noticia de Jesús. España: Editorial Verbo Divino.

Ska, J. (2008). Una goccia d'inchiostro. Bologna: Centro editoriale Dehoniano.

Talbott, R. F. (January, 2006). Imagining the Matthean eunuch community. Kyriarchi on the Chopping Block. Journal of Feminist Studies in Religion. 22.1. 